\title{
Importance of Scaffolding
}

Priya Khatri ${ }^{1}$

Writing across the University of Alberta, $2021^{2}$

Volume 2, pp. 33-36

Published December 2021

\section{Introduction}

WRS 101 was the first writing course I had ever taken, so I didn't know what to expect. When I saw the first assignment about genre analysis, I felt a sudden sense of panic. I had no idea what genre meant in an academic setting. Yet, as the class progressed, I quickly realized I wasn't expected to be an expert, as there is a zone of proximal development (ZPD), which is the distance between what I can do and the next learning that I could achieve with competent assistance (Raymond 176). Through scaffolds provided by the professor, I overcame the ZPD and finally applied unfamiliar concepts.

Vygotsky defined scaffolding instructions as the "role of teachers in supporting the learner's development and providing structures to get to the next level" (Raymond 176). An important feature of scaffolding is its temporary nature, the support of the teacher is gradually withdrawn, and the learner becomes increasingly able to complete tasks alone (Hammond et al.). Thus, scaffolding allows for growth through the usage of both co-dependent and independent learning, ultimately leading to a better comprehension of the topic.

\section{Interdependent Learning: A Social Activity}

Scaffolding enhances the presence of the teacher. The teacher takes over parts of the task that the student cannot perform by setting parameters (Kim \& Hannafin) and simplifying the task (Van Der Stuyf 3). This allows for direct maintenance of learning, as it causes learners to be more focused on achieving each step (Kim \& Hannafin). When completing the first assignment, I found the assignment outline and rubric essential to my

${ }^{1}$ Correspondence: Priya Khatri (pkhatri@ualberta.ca)

${ }^{2}$ Writing across the University of Alberta (WAUA) publishes undergraduate student writing from Writing Studies courses at the University of Alberta. You can find WAUA online at writingacrossuofa.ca. 
learning process. Having each task outlined helped reduce my anxiety, as I was able to see that I was gradually going to reach the goal. Therefore, I only had to concentrate on the task I was currently completing, not on the product. As I was doing each task, I was also able to clarify my understanding of topics I was unsure of, like properly making citations. The rubric also acted as a learning tool, as I felt like it helped me understand the expectations more clearly. I would always reference the rubric when writing as I could figure out what needed to be improved in my writing to complete the step.

The teacher provides models, prompts, hints, partial solutions, and direct instruction (Hartman). The professor provided many sample papers with annotated notes, which provided direct instructions and hints about the requirements for the assignment. Since I was doing rhetorical analysis, I was grateful that the professor had provided us with four different sample papers. Before writing, I read through all the samples and compared the similarities and differences among them. The similarities provided clues on what I needed to incorporate in my writing. After completing my assignment, I would compare it to the samples, which helped me improve my writing. Not only were outlines and PowerPoints provided but also other multimodal resources like videos and websites. These provided additional support with cognitive structuring (Kim \& Hannafin), which provides meaning and organization to experiences and guides the processing and retrieval of new information ("Cognitive Structure"). When I learned a new concept, it was hard for me to understand how to implement them, especially the concept of argument organization. The professor had put extra videos, and I quickly found them on eClass. The video provided was beneficial, as it gave actual examples and a step-by-step method to identify a strong argument versus a weak one. After having a better grasp of the concept, I was able to create a detailed schema quickly. This further shows the importance of resources and the presence of the teacher.

It's evident that scaffolding is an interdependent activity; therefore, group learning is another essential aspect. Collaborative learning allows students to work together to solve problems or complete tasks (Laal and Ghodsi 487). These discussions can result in higher productivity and critical thinking. Group discussions allowed me to build on the topics taught and were key aspects of this course. Each group-writing assignment provided me with an opportunity to learn from my peers and clarify my understanding. This was remarkably helpful when we were "marking" a sample paper. While "marking," I would always put everything as "satisfactory," but my group member pointed out crucial details about paragraphs that would make it "good." Though I was a bit adamant about my position, she convinced me after a conversation and taught me the difference between the grades. This discussion helped me create strategies to become a better peer-reviewer and self-reviewer. 
As the ability of the learner increases, the scaffolding is progressively withdrawn (Chang, Sung, \& Chen 7). Therefore, independent learning is facilitated through scaffolding. Metacognitive coaching is an important result of scaffolding as it allows learners to identify and modify their learning to create problem-solving techniques (Kim \& Hannafin). Scaffolding breaks down tasks into achievable steps, making identifying problems easier. For example, when writing my module 1 assignment, I was worried about implanting the techniques used to identify rhetorical strategies. At first, I tried finding the logos, pathos, and ethos for one sample simultaneously, but it ended up being confusing. I decided to come back after completing everything else. When I went back, I realized that I had to compare the methods used in each sample. I decided to identify one technique (logos, ethos, or pathos) in the samples at a time, compare them, and then move on to the next technique.

Scaffolding each step reduces uncertainty, surprise, and disappointment so learning can be maximized (McKenzie). This is exactly how I felt throughout the writing process, as I knew what to expect at each step. I wasn't surprised to see the assignment's requirements since we had worked on mini assignments with the concepts in class. These low-risk assignments allowed me to practice new skills without being shocked during the essay. It felt gratifying as I finished each step, as I knew I was one step closer to completing the assignment. Efficiency is delivered as the work is structured and focused, and glitches are reduced or eliminated. The time the task requires is decreased as momentum is created. Students spend less time searching and more time learning and applying concepts, which results in quicker learning (McKenzie). Since I already knew about each topic like pathos, I spent more time implementing rather than explaining learned concepts, as I could assume that everyone in the class knew them, which helped reduce frustration. Though we only had about two weeks to complete the assignment, after we learned about each concept, I could still complete a decent draft in time as I had the drive to finish the task.

Overall, scaffolding motivates independent interest related to the task (Van Der Stuyf 11). By providing structure, the scaffolded lesson provides pathways for the learners. The student can decide which path to choose or what to explore along the path, but they cannot wander off the path, which is the designated task (McKenzie). Due to the scaffolds provided, I had a clear pathway that led to the completion of the assignment. Though I didn't have much choice about what I wanted to complete, as it was either rhetorical or linguistic analysis, it was okay since this was my first writing course. I was nervous about the writing, but I could still explore many new concepts that I had never heard of before, like genre analysis. I also couldn't "wander off the path" as each section was essential for the assignment, but I was exposed to so many new concepts that it didn't matter if I could 
deviate off the path too much. I am now confident in applying techniques like paraphrasing and citing to other courses and assignments.

\section{Works Cited}

Benson, Beth Kemp. "Scaffolding (Coming to Terms)." English Journal, vol. 86, no. 7, 1997, pp. 126-127.

Chang, Kuo-En, Yao-Ting Sung, and Ine-Dai Chen. "The Effect of Concept Mapping to Enhance Text Comprehension and Summarization." The Journal of Experimental Education, vol. 71, no. 1, 2002, pp. 5-23.

"Cognitive Structure." Encyclopedia of the Sciences of Learning, edited by Norbert M. Seel, Springer, 2012, p. 619. https://doi.org/10.1007/978-1-4419-1428-6_2071.

Hammond, Jennifer, and Pauline Gibbons. "What is Scaffolding?" Teachers' Voices 8: Explicitly Supporting Reading and Writing in the Classroom, edited by Anne Burns and Helen de Silva Joyce, Macquarie University, 2005, pp. 8-16.

Hartman, Hope. Human Learning and Instruction, 2005. ResearchGate. https://www.researchgate.net/publication/313360794_Human_Learning_and_Instruction.

Kim, Minchi C., and Michael J. Hannafin. "Scaffolding 6th graders' Problem Solving in Technology-Enhanced Science Classrooms: A Qualitative Case Study." Instructional Science, vol. 39, no.3, 2011, pp. 255-282. https://doi.org/10.1007/s11251-010-9127-4.

Laal, Marjan, and Seyed Mohammad Ghodsi. "Benefits of Collaborative Learning." Procedia: Social and Behavioral Sciences, vol. 31, 2012, pp. 486-490. https://doi.org/10.1016/i.sbspro.2011.12.091.

Lindstrøm, Christine, and Manjula D. Sharma. "Teaching Physics Novices at University: A Case for Stronger Scaffolding." Physical Review Physics Education Research, vol. 7, no. 1, 2011. https://doi.org/10.1103/PhysRevSTPER.7.010109.

Raymond, Eileen. "Cognitive Characteristics." Learners with Mild Disabilities: A Characteristics Approach, Pearson, 2000, pp. 169-201.

Van Der Stuyf, Rachel R. Scaffolding as a Teaching Strategy, 2002. Academic.edu. https://www.academia.edu/download/58867028/Scaffolding_as_a_Teaching_Strategy2019041 1-39375-kajifs.pdf.

(c) $(\bigoplus$ This work is licensed under CC BY-NC-ND 4.0. To view a copy of this license, visit https://creativecommons.org/licenses/bv-nc-nd/4.0. 